\title{
Shaping ability of 2Shape and NeoNiTi rotary instruments in preparation of curved canals using micro-computed tomography
}

\author{
Ibrahim Faisal| ${ }^{*}$, Rajab Saif ${ }^{1}$, Mona Alsulaiman ${ }^{1}$ and Zuhair S. Natto ${ }^{2}$
}

\begin{abstract}
Background: Various systems of nickel-titanium (NiTi) instrument have long been commercially available. However, the preparation of narrow and curved root canals has always been challenging. The purpose of this study was to compare the shaping ability of two NiTi systems (2Shape and NeoNiTi) in severely curved root canals with different morphological patterns using micro-computed tomography (Micro-CT).

Methods: A total of 22 human extracted permanent teeth of mandibular first molars, with the exact mesial angle of curvature of 25 and 35 degrees, according to Schneider's technique, were distributed randomly into two groups (group I: 2Shape, group II: NeoNiTi) based on the rotary system used $(n=22)$. The groups were subdivided into two subgroups corresponding to the angle of canal curvature $\left(25^{\circ}\right.$ and $\left.35^{\circ}\right)(n=11)$. Canals were scanned using MicroCT pre- and post-preparation to assess the volume of dentin removed; canal transportation; and canal centering ratio at 3, 6, and $9 \mathrm{~mm}$ from the apex. The Mann-Whitney $U$ test was utilized to determine any significant differences between the two systems. The level of statistical significance was set at $p<0.05$.
\end{abstract}

Results: There was no significant difference between the two groups in volume of dentin removed; canal transportation; and centering ability for $25^{\circ}$ and $35^{\circ}$ canal curvatures at 3, 6, and $9 \mathrm{~mm}$ from the apex (coronal, middle, and apical) thirds ( $p>0.05$ ). At the middle third, the NeoNiTi group demonstrated a statistically significant increase in volume of dentin removed for $35^{\circ}$ canal curvatures compared to the 2Shape group.

Conclusion: Within the limitation of our in vitro study, 2Shape and NeoNiTi systems with severely curved canals were confirmed to be relatively safe in preparation and to respect original canal anatomy. Nevertheless, NeoNiTi instruments produced more centered preparation and minimal canal deviation compared to the 2Shape system.

\section{Background}

Root canal shaping is a necessary step for successful endodontic therapy. Endodontic treatment is aimed at the elimination of periapical bacteria, which is caused by root canal disease. This is achieved by the chemomechanical preparation of the root canal system $[1,2]$. It is essential to maintain the canal's original form as far as

\footnotetext{
*Correspondence: dr.ibrahimdentist@hotmail.com

${ }^{1}$ Department of Endodontics, Faculty of Dentistry, King Abdulaziz

University, Jeddah, Saudi Arabia

Full list of author information is available at the end of the article
}

possible while the root canal is gradually widened from the apical to the coronal region [3].

Various systems of nickel-titanium (NiTi) instruments have been available in the market. These instruments can help in the mechanical and biological preparations [4]. Nickel-titanium (NiTi) rotary instruments produce the canal after a more centered preparation, with less deviation than other instruments [5]. However, the preparation of narrow and curved root canals has always been a challenge, due to the tendency of the canal to deviate from its normal axis after preparation [6]. Besides, the curvature introduces a complexity that influences 
instruments' ability to prepare and clean all root canal walls regardless of the instrumentation system used [7, 8]. These difficulties in preparation may predispose to persistent root canal infection, with a consequent risk for treatment outcome [9].

2Shape (Micro-Mega, Besancon, France) is a sequence with two shaping files in continuous rotation which have been heat treated using $\mathrm{T}$ Wire technology [10, 11]. According to the manufacturer, the flexibility of instruments increases user comfort $[10,11]$ and facilitates an excellent negotiation of curvatures with the instruments, which return to their initial shape after each use $[10,11]$. The file has an asymmetrical cross-section that offers superior cleaning of the root canal walls with two main and one secondary cutting edges $[10,11]$. These edges increase the cutting efficiency of the file and improve debris removal. The $2 \mathrm{~S}$ system is composed of TS1 (25/0.04), TS2 (25/0.06), F35 (35/0.06), and F40 $(40 / 0.04)$ files $[10,11]$.

NeoNiTi (Neolix, France) is manufactured with a wirecut electrical discharge machining (EDM) process and is used to prepare the root canal until the apex. The advantages of this (EDM) technique of the NeoNiTi file system are minimal residual stresses, a high level of accuracy, and more advanced surface finishing [12].

The features of alloys are affected by receiving EDM processes for instance fatigue resistance [13] and surface hardness [14]. Moreover, the flexibility of these files improved compared to files in a proper heat treatment process. It has a non-homothetic rectangular cross-section and consists of one file $\mathrm{C} 1$ for enlargement of the coronal part and three A1 files with different tip sizes of $\# 20$, \#25, and \# 40 for canal preparation until the apex. It provides the ideal shape of canals to receive the guttapercha filling $[15,16]$.

To our knowledge, few studies have compared instruments composed of a wire-cut electrical discharge machining (WEDM) process NiTi alloy and those composed of the T-Wire heat-treated NiTi alloy in different canal morphology. Hence, our study aimed to investigate the shaping ability of 2Shape and NeoNiTi rotary NiTi systems in the preparation of curved canals using microcomputed tomography (Micro-CT). The null hypothesis is there is no difference in shaping ability between the two experimented file systems in shaping canals with different morphological patterns.

\section{Methods}

\section{Sample selection}

This study was conducted with approval from the Research Ethics Committee (\#113-11-20) at King Abdulaziz University, Jeddah, KSA. This is a pilot study for which a total of 22 human extracted permanent teeth of mandibular first molars with mesial curved root canals were collected from the Oral and Maxillofacial Surgery department in the faculty of dentistry, King Abdulaziz University. The teeth were extracted for periodontal or prosthodontic reasons. The patients were of unknown gender and age.

Inclusion criteria were as follows: all teeth had two separate canals in the mesial root (mesiobuccal and mesiolingual) as confirmed by digital periapical radiographs from the Carestream (CS) R4 Clinical and Practice Management Software (CS Health, Inc. Rochester, NY, USA) in a mesiodistal and buccolingual direction with two separate apical foramen (Vertucci type IV configuration). Teeth with fully formed apices and a standardized root canal curvature of $25^{\circ}$ and $35^{\circ}$, measured according to Schneider's technique [17] using digital buccolingual radiographs. There were no signs of calcification in the root canal, root caries, nor internal or external root resorption. The experimental conditions in our study did not require isolation. Thus, we excluded a control group in this situation. The teeth were cleaned using an ultrasonic scaler (P5 Newtron, Satelec, Acteon, France) and disinfected in $0.1 \%$ thymol (Merck, Germany), after which they were preserved in $0.5 \%$ Chloramine solution at $4{ }^{\circ} \mathrm{C}$ until future use. To prepare a $0.5 \%$ Chloramine solution, due to the presence of crystallized water in its salt structure, the amount of $0.63 \mathrm{~g}$ of solid Chloramine was dissolved in distilled water, bringing its volume to $10^{-4} \mathrm{~m}_{3}$. To prepare a solution of $0.01 \%$ of Thymol, $1 \mathrm{mg}$ of solid Thymol was dissolved in 96\% ethanol, bringing its volume to $10^{-4} \mathrm{~m}_{3}$.

\section{Sample preparation}

The teeth specimens were decoronated at the level of cemento-enamel junction under a water-cooling system to a standardized root length of $18 \mathrm{~mm}$ under $10 \times$ magnification in a surgical operating microscope (Carl Zeiss OPMI Pro Ergo, Germany).

A high-speed diamond bur (Dentsply Sirona, Ballaigues, Switzerland) was used to prepare the access cavity. K-file size 10 (Dentsply Maillefer) was used in the mesiobuccal and mesiolingual canals to check patency under (10x) magnification of the dental operating microscope (Carl Zeiss OPMI Pro Ergo, Germany). The working length was measured up to $1 \mathrm{~mm}$ coronal to apical foramen.

Root apices of each mesial root were sealed with utility wax (Kerr, Orange, Calif.) to preserve the apical foramen from rubber base material penetration. Teeth specimens were mounted in a labeled custom-made resin 6 X6 using a rubber base impression material (Kerr, Orange, Calif.), mixed according to the manufacturer's instructions, to hold and accurately position and standardize each 
specimen for Micro-CT. A landmark placed on the sample holder was used to guarantee the same position for pre-operative and post-operative scan. All experimental samples were scanned before instrumentation using the micro-computed tomography system (NRecon Skyscan model 1172) (Kontich, Belgium) using acquisition parameters $90 \mathrm{kV} / 112 \mathrm{~mA}$. The voxel size of the data following reconstruction was $13.73 \mu \mathrm{m}$.

\section{Root canal preparation}

The samples were randomly distributed according to the system (group I: 2Shape and group II: NeoNiTi) into two experimental groups. The mesiobuccal canal was used for the 2Shape system and mesiolingual canal was used for the NeoNiTi system. Both groups were subdivided according to the angle of root canal curvature into two subgroups based on whether the root canal curvature was $25^{\circ}$ or $35^{\circ}$.

The preparation was conducted by one operator according to the manufacturer's recommendation. In all groups, the instruments were discarded after single use. Endodontic motor (X-smart, Dentsply Maillefer) was used according to the manufacturer's instructions during root canal preparation for each file system. The preparation was carried out in a crown-down sequence, where the file moved with light apical pressure of about $3 \mathrm{~mm}$ in a slow in-and-out pecking motion and extreme torque set at $1.5 \mathrm{~N} / \mathrm{cm}$ and clockwise continuous rotary motion set at $300 \mathrm{rpm}$. The process was performed again in all systems until the full working length was reached. During procedure, the canals were irrigated with $2 \mathrm{~mL} 5.25 \%$ $\mathrm{NaOCl}$ for 1 min between each file using a side-vented, 30-gauge needle (Ultradent, South Jordan, UT). A \#10 K-file was utilized to provide apical patency between each rotary file. Paper point was used to dry the canals, after which an additional rinse with $2 \mathrm{~mL} 17 \%$ EDTA was performed after instrumentation, followed by the final irrigation using distilled water (DW; $5 \mathrm{~mL}$ ). After irrigation, the canals were dried using absorbent paper points (Dentsply Sirona Endodontics).

\section{Process of micro-CT and assessment protocol}

The Micro-CT device model used to obtain X-ray images of the specimens was NRecon Skyscan model 1172 Version 1.6.4 (Kontich, Belgium). For each sample, three cross-sectional slices from the apical foramen distance were chosen (before and after instrumentation) as follows: apical third considered as $3 \mathrm{~mm}$ distance from the anatomic apex, middle third considered as $6 \mathrm{~mm}$ distance from the anatomic apex, and coronal third considered as $9 \mathrm{~mm}$ distance from the anatomic apex $[18,19]$. The volume of dentin removed for each root canal was measured in $\mathrm{mm}^{3}$ by subtracting the canal volume before preparation from the canal volume after preparation [20]. Canal transportation and centering ratio were calculated at 3-, 6-, and 9-mm levels from the root apex according to the formula: $(\times 1-\times 2) /(\mathrm{y} 1-\mathrm{y} 2)$ or $(\mathrm{y} 1-\mathrm{y} 2) /(\times 1-\times 2)$ as described by Gambill et al. [21].

Initially, all teeth were scanned in a particular sample holder to ensure repositioning of the specimens and thus guarantee repeated measurements. Source of the X-ray was set to $90 \mathrm{kV} / 112 \mathrm{~mA}$ and a $0.05 \mathrm{~mm}$ aluminum filter was utilized to scan all specimens, to minimize scattering and artifacts of beam hardening. Each sample in the machine was rotated 360 degrees with an integration time of $5900 \mathrm{~ms}$ per projection. The voxel size of the data reconstructed was $13.73 \mu \mathrm{m}$. These settings were applied to measurements of the teeth and follow-up procedure.

CT-Analyser (CTAn) V.1.11 (Skyscan) software was applied to establish 3-D visualization and analysis of morphological parameters of the mesial canals (volume of dentin removed, canal transportation, and centering ability).

Two Micro-CT images were produced as pre-instrumentation scan, which was carried out for all evaluated teeth samples, and post-instrumentation scan. The latter scan was performed using previous parameters and positions to achieve a comparison between samples.

\section{Qualitative assessment}

This assessment was performed by superimposing 3D images and fabricating a red-color image for an unprepared area and blue-color image for the prepared area. Furthermore, we presented cross-section of images for certain slices and clarified for each part of the experiment.

\section{Quantitative assessment Volume of dentin removed}

The canals' pre- and post-preparation volumes were calculated separately using CT-Analyser (CTAn) V.1.11 software to fabricate a relevant $3 \mathrm{D}$ area of interest. The changes in canal volume for each root canal were calculated at $\mathrm{mm}^{3}$ by subtracting the unprepared canal volume from the prepared canal volume and comparing between the two groups.

\section{Canal transportation}

Direction and range of canal transportation in $\mathrm{mm}^{3}$ were calculated from axial sections congruous to distances of 3,6 , and $9 \mathrm{~mm}$ from the root apex, according to the formula presented by Gambill et al. [21]. The measurement of canal transportation was determined by comparing the distance between the unprepared canal edge to the tooth edge and the prepared canal edge to the tooth edge in mesial and distal directions. ${ }^{21}$ The canal transportation 
was calculated using the following formula: Mesiodistally $=(x 1-\times 2)-(y 1-y 2)$ as the following: $X 1$ and $\mathbf{X} 2$, indicate the shortest distance between the mesial edge of the root to the unprepared, prepared canal edge, respectively. Meanwhile, Y1 and Y2 indicate the shortest distance between the distal edge of the root to the unprepared and prepared canal edges, respectively.

The formula demonstrated a score of 0 , signifying no canal transportation. A positive score shows mesial (lingual transportation) and a negative score shows distal (buccal transportation).

\section{Centering ratio}

The mean value of centering ratio is a measurement of the capability of the file to remain centered in the canal. The ratio for each section in mesiodistally direction was measured using the following formula described by Gambill et al.: $(\times 1-\times 2) /(y 1-y 2)$ or $(y 1-y 2) /(\times 1-\times 2)$ [21].

The pre-and post-instrumentation scans of samples were superimposed using the software CT-Analyser (CTAn) V.1.11 in the multiplanar viewer. The formula demonstrated a score equal to 1.0, indicating preferable centralization. A ratio value closer to 0 signified that the instrument was less capable of remaining centered in the canal's axis.

One evaluator conducted image analysis for all phases. The resultant data were stored in a database using CTAnalyser (CTAn) V.1.11 (Skyscan).

\section{Statistical analysis data}

The mean $(\mathrm{M}) \pm$ standard deviation $(\mathrm{SD})$ values of volume of dentin removed, canal transportation, and the centering ratio were carried out using IMB SPSS software (version 23, SPSS, Inc., Chicago, Illinois, USA). For nonparametric data, the Mann-Whitney U test was utilized to determine any significant differences between the two systems for the two different morphological patterns. The level of statistical significance was set at $p<0.05$.

\section{Results}

\section{Shaping ability of root canal systems}

This result discussed the effectiveness of two continuous rotation $\mathrm{NiTi}$ instrument systems in the shaping ability of root canal system in different canal's morphology. The comparison between 2Shape and NeoNiTi systems manifested no significant differences regarding volume of dentin removed, canal transportation, or centering ability.

\section{Qualitative assessment}

Figure 1 provides representative Micro-CT images $(\mathrm{A}-\mathrm{C})$ of MB canal prepared by 2 Shape and (D-F) of ML canal prepared by NeoNiTi, before and after preparation, and superimposed pre- and post-preparation image. Figure 2 shows illustrative Micro-CT images (A-C) at different levels (apical, middle, coronal) describing the three-dimensional reconstruction of $\mathrm{MB}$ canal prepared by 2 Shape and ML prepared by NeoNiTi from occlusal plane. Figure 3 presents cross-section images acquired from Micro-CT image pre- and post-preparation from different level slices (apical, middle, coronal).

Figure 4 represents the distance of the curved root surface from the outside to the edges of the unprepared and prepared canals (X1 and X2), respectively. Furthermore, it also represents the distance of the curved root surface from the inside to the edges of the unprepared and prepared canals (Y1 and $\mathrm{Y} 2$ ), respectively.

\section{Quantitative assessment}

During root canal preparation, there was one file fracture from $35^{\circ}$ root canal curvature of the 2Shape subgroup at apical third. This tooth was substituted with another one to maintain sample volume.

\section{Volume of dentin removed Total volume of dentin removed}

The (M) and (SD) values between two groups (2Shape and NeoNiTi) are shown in Table 1. There was no statistically significant difference in the total volume of dentin removed among the root canal for both groups $(p=0.557)$. There was no statistically significant difference in the volume of dentin removed between the two groups at different thirds (coronal third $p=0.557$, middle third 0.398 , and apical third 0.656 , respectively).

\section{$25^{\circ}$ root canal curvature at the different root thirds}

Regarding total volume of dentin removed, there was no statistically significant difference in the volume of dentin removed among the whole root canal for both groups of $25^{\circ}$ root canal curvature $(p=0.899)$ (Table 1). Additionally, there was no statistically significant difference in the volume of dentin removed between the two groups at the different thirds (coronal third $p=0.773$, middle third 0.729 , and apical third 0.525 , respectively).

\section{$35^{\circ}$ root canal curvature at the different root thirds}

There was no statistically significant difference in the volume of dentin removed among the whole root canal for both groups of $35^{\circ}$ root canal curvature $(p=0.450)$ (Table 1). There was also no statistically significant difference in the volume of dentin removed between the two groups at different thirds (coronal third $\mathrm{p}=0.650$, middle third 0.096 , and apical third 0.545 , respectively). 


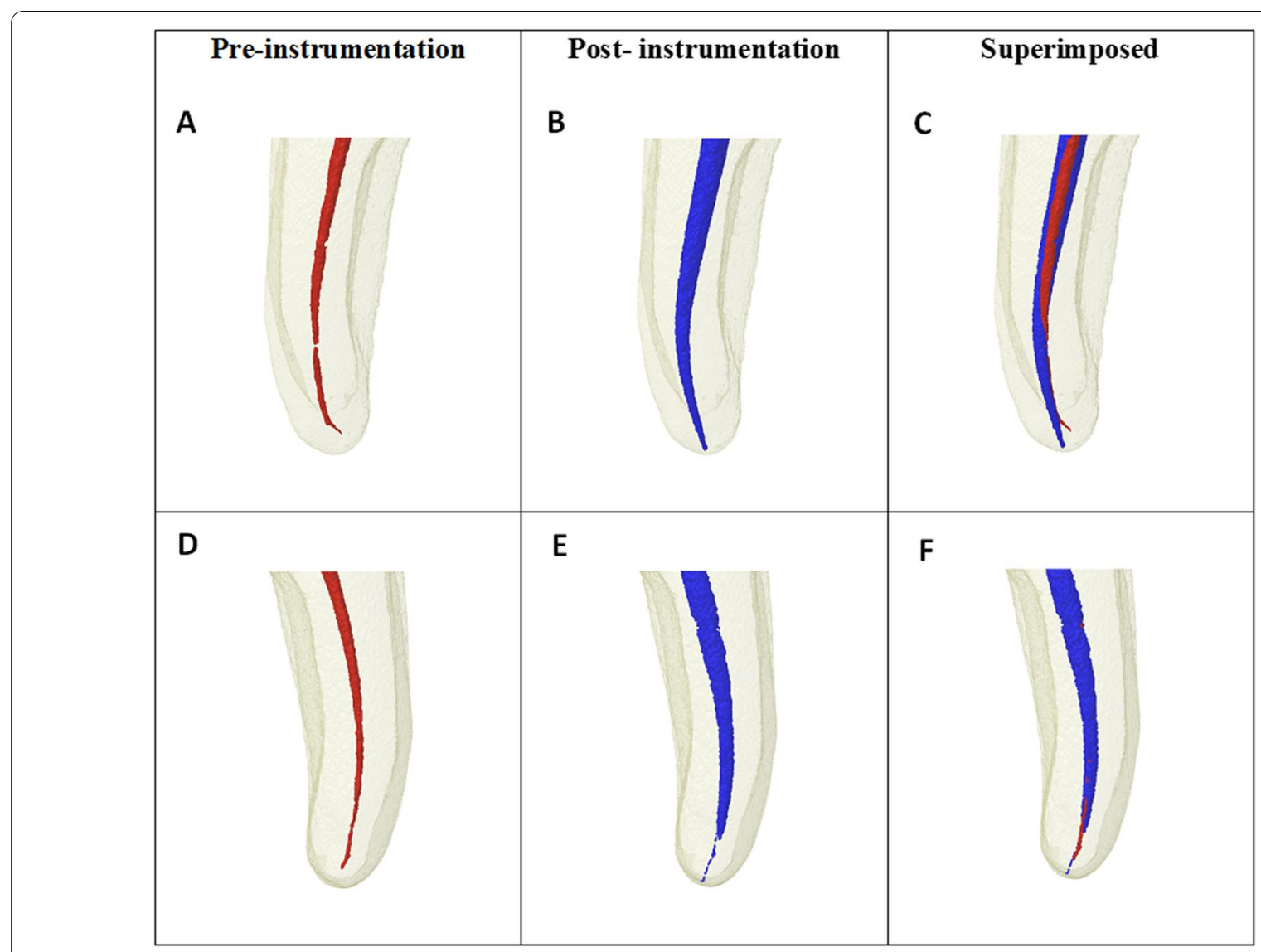

Fig. 1 Representative 3D reconstructed image of mesiobuccal root canal prepared by 2Shape; A pre-preparation; B post-preparation and C superimposed, and mesiolingual root canal prepared by NeoNiTi; $\mathbf{D}$ pre-preparation; E post-preparation and $\mathbf{F}$ superimposed. Note canal before preparation (red) and canal after preparation (blue)

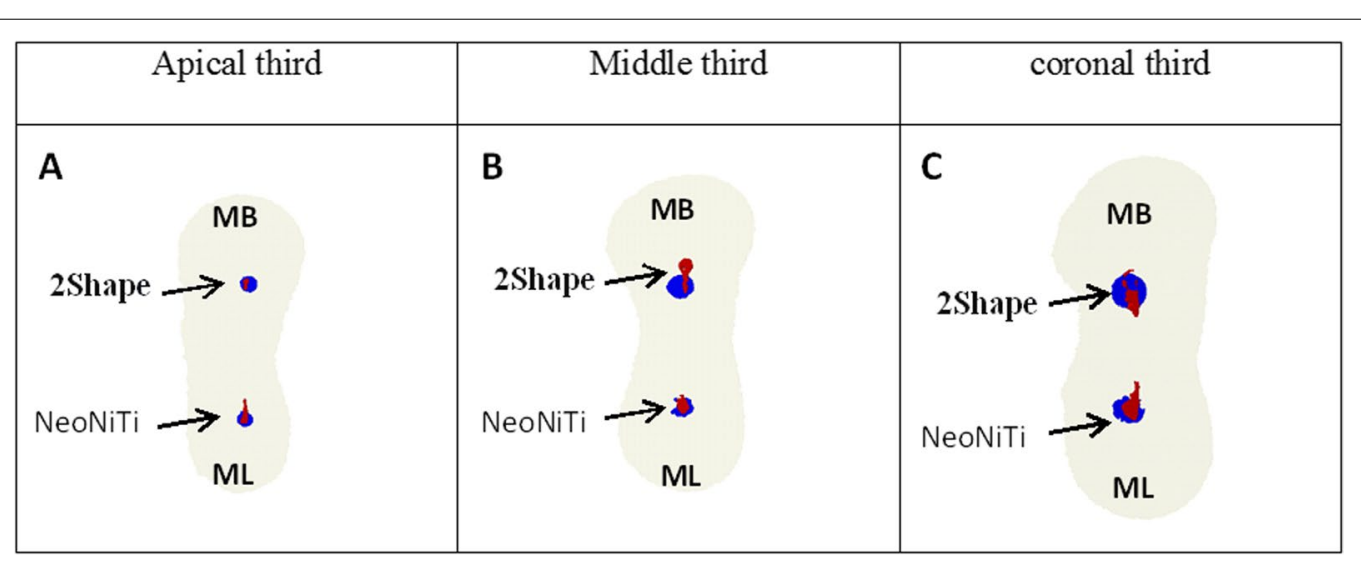

Fig. 2 representative three-dimensional reconstructed images of root canal system for mesiobuccal and mesiolingual canals at different levels prepared by 2 Shape and NeoNiTi, respectively. A Apical; B middle; and C coronal thirds. Note root canal before (red) and after (blue)

\section{Shape $25^{\circ}$ and $35^{\circ}$ root canal curvature at different thirds} There was no statistically significant difference in the volume of dentin removed between $25^{\circ}$ and $35^{\circ}$ root canal curvature at different thirds within the subgroups (coronal third $p=0.510$, middle third 0.644, and apical third 0.323 , respectively) (Table 1 ). 


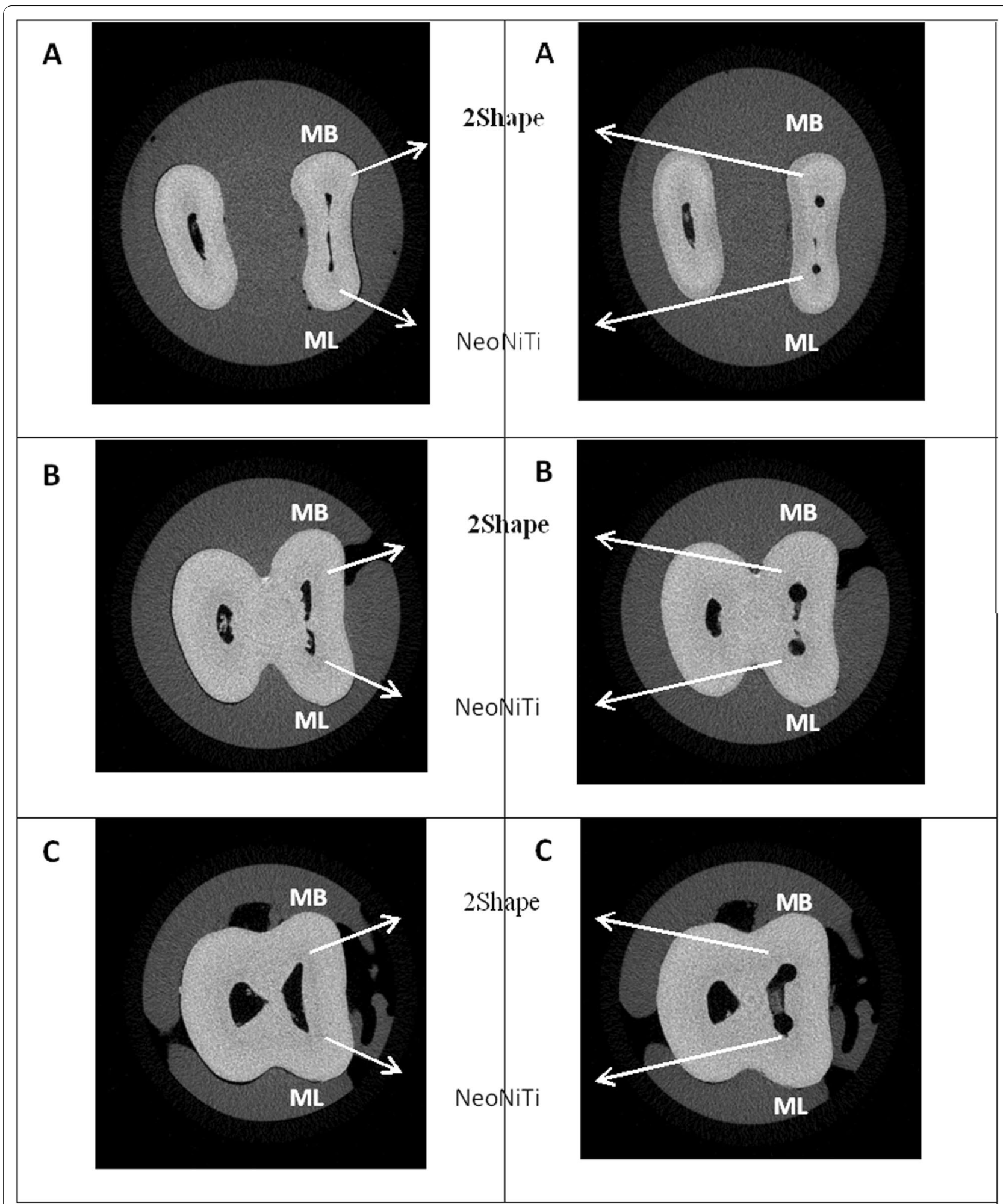

Fig. 3 representative cross section images at different level slices of root canal system for mesiobuccal and mesiolingual canals prepared by 2Shape and NeoNiTi, respectively. Before instrumentation (left side) and post instrumentation (right side). A Apical; B middle; and C coronal thirds 


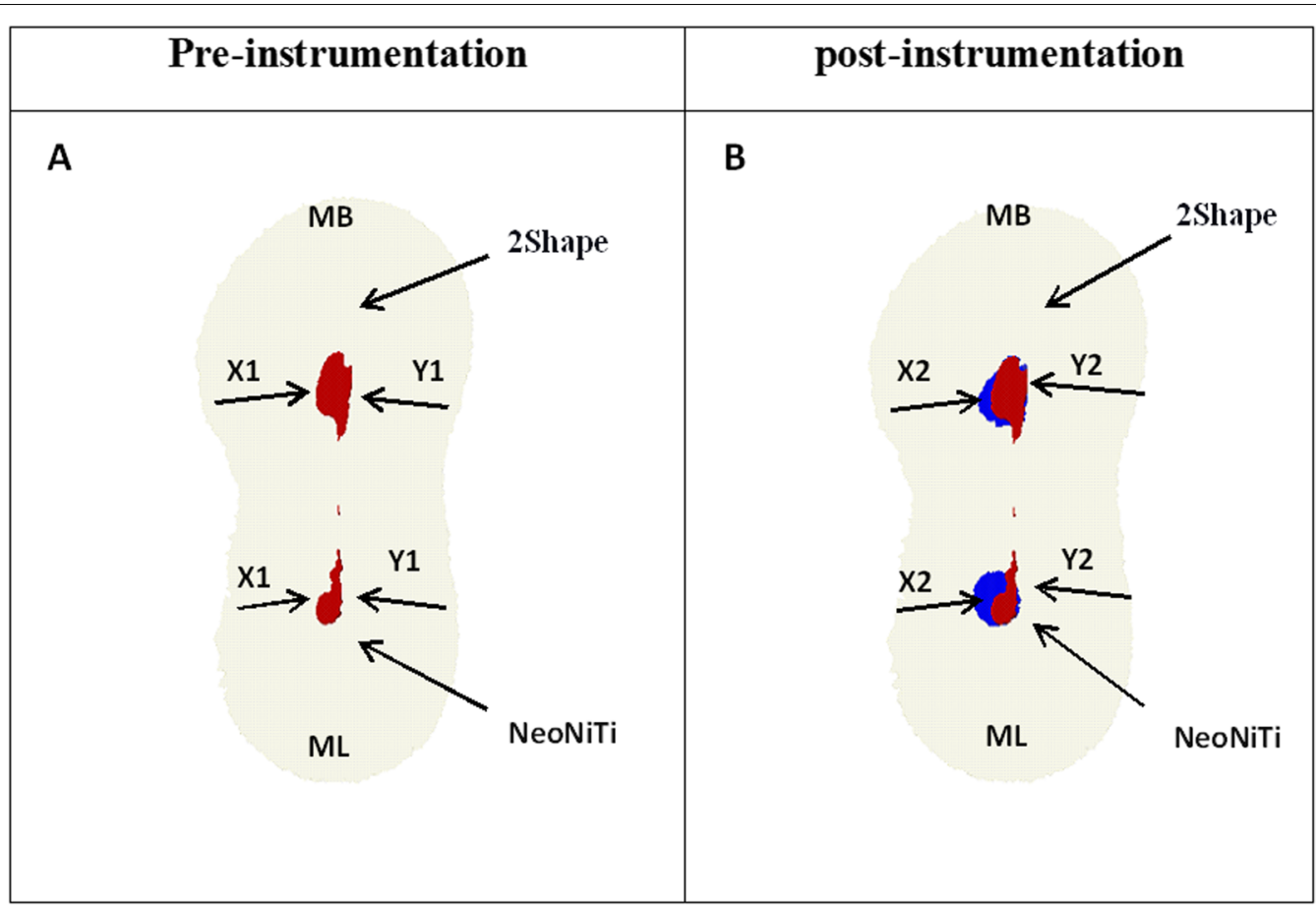

Fig. 4 Representative 3D reconstructed images of root canal system from occlusal plane for mesiobuccal and mesiolingual canals prepared by 2Shape and NeoNiTi, respectively. A Canal before preparation; and B superimposed. X1 and X2 the distal surface of the root of unprepared and prepared canals, respectively. $\mathrm{Y} 1$ and $\mathrm{Y} 2$ the mesial surface of the root of the unprepared and prepared canals, respectively

Table 1 The Mean \& standard deviation of volume of dentin removed canal transportation and centering ratio of $25^{\circ}$ and $35^{\circ}$ root canal curvature prepared by (2Shape \& NeoNiTi)

\begin{tabular}{|c|c|c|c|c|c|c|c|c|c|c|}
\hline Section & Parameter & $25^{\circ} 2$ Shape & $\begin{array}{l}25^{\circ} \\
\text { NeoNiTi }\end{array}$ & $p$ value $^{1}$ & $35^{\circ} 2$ Shape & $35^{\circ} \mathrm{NeoNiTi}$ & $p$ value $^{2}$ & $p$ value $^{3}$ & $p$ value $^{4}$ & $p$ value $^{5}$ \\
\hline \multirow[t]{3}{*}{ Coronal } & Volume & $0.63 \pm 0.37$ & $0.68 \pm 0.32$ & 0.773 & $0.81 \pm 0.47$ & $0.95 \pm 0.52$ & 0.650 & 0.510 & 0.262 & 0.557 \\
\hline & Transportation & $0.33 \pm 0.22$ & $0.27 \pm 0.24$ & 0.507 & $0.31 \pm 0.19$ & $0.32 \pm 0.12$ & 0.734 & 0.843 & 0.222 & 0.647 \\
\hline & Centering ratio & $2.88 \pm 1.93$ & $2.82 \pm 2.40$ & 0.741 & $3.41 \pm 1.66$ & $3.65 \pm 2.48$ & 0.847 & 0.630 & 0.457 & 0.425 \\
\hline \multirow[t]{3}{*}{ Middle } & Volume & $0.31 \pm 0.17$ & $0.30 \pm 0.15$ & 0.729 & $0.39 \pm 0.28$ & $0.54 \pm 0.27$ & 0.096 & 0.644 & $0.030^{*}$ & 0.398 \\
\hline & Transportation & $0.14 \pm 0.17$ & $0.06 \pm 0.10$ & 0.106 & $0.09 \pm 0.13$ & $0.07 \pm 0.10$ & 0.578 & 0.206 & 0.604 & 0.087 \\
\hline & Centering ratio & $3.04 \pm 0.13$ & $1.54 \pm 2.02$ & 0.078 & $2.42 \pm 2.30$ & $1.58 \pm 1.66$ & 0.683 & 0.171 & 0.940 & 0.127 \\
\hline \multirow[t]{3}{*}{ Apical } & Volume & $0.08 \pm 0.05$ & $0.07 \pm 0.03$ & 0.525 & $0.09 \pm 0.13$ & $0.08 \pm 0.09$ & 0.545 & 0.323 & 0.323 & 0.656 \\
\hline & Transportation & $0.07 \pm 0.08$ & $0.09 \pm 0.15$ & 0.624 & $0.04 \pm 0.24$ & $0.15 \pm 0.19$ & 0.364 & 0.792 & 0.644 & 0.725 \\
\hline & Centering ratio & $0.80 \pm 1.03$ & $0.74 \pm 0.54$ & 0.419 & $1.31 \pm 2.06$ & $1.49 \pm 1.82$ & 0.762 & 0.553 & 0.843 & 0.411 \\
\hline \multirow[t]{3}{*}{ Total } & Volume & $0.34 \pm 0.18$ & $0.35 \pm 0.27$ & 0.899 & $0.43 \pm 0.27$ & $0.52 \pm 0.28$ & 0.450 & 0.510 & 0.147 & 0.557 \\
\hline & Transportation & $0.18 \pm 0.08$ & $0.14 \pm 0.07$ & 0.126 & $0.12 \pm 0.14$ & $0.08 \pm 0.08$ & 0.882 & 0.582 & 0.356 & 0.227 \\
\hline & Centering ratio & $2.51 \pm 0.96$ & $1.87 \pm 1.44$ & 0.149 & $2.38 \pm 1.08$ & $2.02 \pm 1.06$ & 0.916 & 0.234 & 0.501 & 0.280 \\
\hline
\end{tabular}

${ }^{1} p$ value using Mann-Whitney $\mathrm{U}$ between $25^{\circ} 2$ Shape and $25^{\circ} \mathrm{NeoNiTi}$

${ }^{2} p$ value using Mann-Whitney $\mathrm{U}$ between $35^{\circ} 2$ Shape and $35^{\circ} \mathrm{NeoNiTi}$

${ }^{3} p$ value using Mann-Whitney $\mathrm{U}$ between $25^{\circ} 2$ Shape and $35^{\circ} 2$ Shape

${ }^{4} p$ value using Mann-Whitney $\mathrm{U}$ between $25^{\circ}$ and $35^{\circ} \mathrm{NeoNiTi}$

${ }^{4} p$ value using Mann-Whitney $\mathrm{U}$ between NeoNiTi and NeoNiTi

${ }^{*} p$ value $<0.05$ 


\section{NeoNiTi $25^{\circ}$ and $35^{\circ}$ root canal curvature at different thirds}

There was a statistically significant difference in the value of dentin volume removed between $25^{\circ}$ and $35^{\circ}$ root canal curvature at the middle third $(p=0.030)$ (Table 1$)$. On the other hand, at the coronal and apical thirds, there was no statistically significant difference in the volume of dentin removed between $25^{\circ}$ and $35^{\circ}$ root canal curvature within the subgroups (coronal third $\mathrm{p}=0.262$ and apical third 0.323 , respectively).

\section{Canal transportation}

There was no statistically significant difference in the amounts of mesiodistal transportation between all the parameters investigated for volumes at different thirds (Table 1).

\section{Centering ratio}

There was no statistically significant difference in the total centering ratio of mesiodistal direction among the root canal between all the parameters investigated for volumes at different thirds (Table 1).

\section{Discussion}

The potential of canal transportation during root canal preparation can be reduced by utilizing advanced metallurgy of rotary systems to improve the canal preparation, preserve the canal geometry, and minimize the incidence of mishaps [22]. Several issues may arise during canal preparation procedures, such as perforation, ledge formation, canal blockage, elbow, canal transportation, and a broken file. The systems used in this study were designed to reduce the procedural errors and enhance canal preparation shape. Micro-CT was chosen to assess the alterations in the canal shaping and facilitate comparison between pre- and post-preparation [21, 23, 24]. CT scans are also used in the endodontics field to assess the preparation of root canals using stainless steel hand endodontic instruments and nickel-titanium (NiTi) and compare the endodontic features of dentin removal, canal transportation, and centralization of the files after canal preparation [21].

In the present study, we highlighted the effectiveness of a newly designed instrument representing a new generation of rotary systems in shaping changes in root canal. We focused on two relatively new rotary nickel titanium with similar kinematics during instrumentation and a different cross-section, manufactured by proprietary heat treatment and used as single-file nickel titanium system that required only one instrument for shaping the root canal. Therefore, preparation requires less time than fullsequence rotary instruments [25].

The 2Shape instrument (TS) system is made from (T-wire) technology, which enhances the flexibility of instruments and fractures resistance $[10,11]$. The instrument consists of two main and one secondary cutting edge and non-cutting safety tip for better negotiation of canal curvature. The two cutting edges demonstrated an excellent cutting performance, and the secondary cutting edge enhanced the removal of debris.

On the other hand, NeoNiTi instruments are a newly introduced nickel titanium rotary system made from a controlled memory (CM) nickel titanium wire and manufactured by electrical discharge machining (EDM) [26]. This method contains some considerable advantages. For instance, the rough surface can enhance the cutting efficiency of the file and heat treatment, resulting in high flexibility and increased cyclic fatigue resistance [27].

Shaping ability was evaluated based on three parameters that significantly affect the success of root canal therapy: the volume of dentin removed, canal transportation, and centering ability. The volume of dentin removed from the canal's 3D geometry were evaluated separately at three different levels to determine the differences in canal shape after preparation of the interested area.

Canal transportation match to the post instrumentation deviation in the axis was similar to the original pre-instrumentation axis. The American Association of Endodontists clarified transportation of the canal as "excessive removal of the outside curve of the canal wall that occur because of the orientation of the files to return to their primary shape" [28]. Centering ability refers to the capability of the file axis to align with the canal center, thereby avoiding canal ledging, zipping, or perforation during root canal treatment [29].

In maintaining the torsional properties of M-Wire, the alloy has to be significantly more cyclically fatigueresistant than conventional NiTi alloy [30]. The improved fatigue resistance is attributed to a developed resistance of fracture beginning related to the reorientation ability of the martensitic phase variations [31].

KT Ceyhanli et al. used stereoscopic images to compare the effects of shaping between two types of $\mathrm{NiTi}$ alloy, traditional (ProTaper Universal, Sendoline S5), and M-Wire (WaveOne, GT series X). The manufacturing processes (M-Wire or traditional NiTi) were not found to influence the shaping capability of the systems. The small tapered file systems design resulted in lower deviations of the file during root canal preparation and less removed of material than highly tapered NiTi systems [32].

Zhi Cui et al. used M-CT to assess the shaping ability of two NiTi instrument systems (ProTaper Next and Wave One) in S-shaped canals. They found that there was no significant difference between the two systems at the cervical third. However, the WaveOne system at the apical third caused more transportation than the ProTaper Next system [33]. 
CM Wire files have a significantly improved resistance to cyclic failure than conventional and M-Wire NiTi instruments [34], which might be attributed to the failure of a deflection angle is lower than conventional and M-Wire NiTi [35].

Mozzami et al. assessed the canal transportation of two systems of NiTi instruments (CM Wire: NeoNiTi and M Wire: Reciproc) using (CBCT) as an evaluation method. They realized a significant difference between the systems regarding canal transportation. NeoNiTi produced less transportation than Reciproc in both mesiodistal and buccolingual orientations [36].

Forghni et al. assessed the root canal shaping ability of NeoNiTi and Protaper Universal nickel-titanium endodontic instrument systems using superimposed digital images ofseverely curved simulated canals.The results showed that no significant differences among the systems in changes of canal angle. However, the canal deviation of the Neolix system showed less than the protaper Universal system [37].

In our study, extracted first molars of mandibular teeth with severe mesial root curvatures were used to simulate clinical conditions, rather than simulated artificial canals, due to the natural anatomical features and dentin properties of root canal teeth.

Two separate canals were selected because they were narrow and curved, which increased the difficulty of instrumentation [38]. The samples had similar preoperative geometric parameters, namely, initial apical diameter ( $\mathrm{K}$ file \#10), length characteristic $(18 \mathrm{~mm})$, and angle of curvature $\left(25^{\circ}\right.$ and $\left.35^{\circ}\right)$. Measurement of the root curvature of the teeth was achieved using Schneider's technique [17], which is the most common method of measuring root canal curvature in the literature [39]. The curvatures of all root canal were $25^{\circ}$ and $35^{\circ}$ to adequately standardize the experimental groups, as curvature can influence the shape of canal preparation [40]. The teeth were then randomly distributed between groups (2Shape and NeoNiTi) based on root canal curvature. We used both systems in the same specimen (mesiobuccal and mesiolingual) to standardize the comparison between the two systems.

No articles were found in the literature that used the same two standardized angles as our study. Instead, all previous studies (e.g., Capar et al.) showed angles at a severe curvature, between $20^{\circ}$ and $40^{\circ}$.

Sodium hypochlorite $(\mathrm{NaOC} 1)(5.25 \%)$ was used as the irrigation solution during chemo-mechanical preparation, at the most common concentration used in routine endodontic therapy. A 30-gauge needle size tip was inserted up to 1-2 $\mathrm{mm}$ short of the length to facilitate the irrigant's introduction to the apical third [41], followed by $2 \mathrm{ml}$ of $17 \%$ EDTA after instrumentation to simulate the clinical conditions $[41,42]$. To obtain comparable results, the apical preparation diameter was similar in all samples to size 25 represented by TS2 in the 2 Shape group and A1 in the NeoNiTi group [43].

In this study, the prepared canal was evaluated at three levels: 3,6 , and $9 \mathrm{~mm}$ from the root apex (apical, middle, and coronal thirds) [44]. These levels are highly susceptible to iatrogenic mishaps [40]. Micro-computed tomography (Micro-CT) was chosen because it is considered as the ideal method for laboratory studies: its practicality, accuracy, reliability, reproducibility, and non-destructiveness allow for effective qualitative and quantitative $3 \mathrm{D}$ evaluation of root canals [45].

In the present study, we observed a significant difference in volume of dentin removed between $25^{\circ}$ and $35^{\circ}$ canal curvatures in the NeoNiTi system. The NeoNiTi reported relatively more volume of dentin removed in the middle third at $35^{\circ}$ canal curvature than at $25^{\circ}$. This could be attributed to a homothetic rectangle cross-section; taper size of A1 NeoNiTi file (0.8); circumferential brushing motion in the coronal and middle third; hard cutting edges; and an abrasive property of the flutes [12], that may cause excessive cutting, thereby aggressing the dentin volume [46]. Meanwhile, 2Shape file at $35^{\circ}$ curvature compared to $25^{\circ}$ did not reveal the same result in dentin volume cutting. Subsequently, we noted that the 2Shape group did not exceed that removal of dentin volume. These results are in consistent with previous articles $[47,48]$.

Singh et al. evaluated the volume of dentin removed, canal transportation, and centering ability of 2Shape (2S) and WaveOne Gold (WOG) at different root levels using cone-beam computed tomography (CBCT). They conclude no significant difference between the NiTi files at various root canal levels [49]. Our study assessed and compared the volume of dentin removed, canal transportation, and centering ability at 3, 6, 9 from the apical foramen, and found that neither 2Shape nor NeoNiTi caused significant transportation.

Similarly, Singh et al. evaluated the volume of dentin removed with 2Shape and Protaper Gold in severe root curvature using CBCT. Results found a significant difference between the 2Shape and ProTaper Gold systems at the $3 \mathrm{~mm}, 5 \mathrm{~mm}$, and $7 \mathrm{~mm}$ level. They concluded that the 2Shape file has the less aggressive removal of dentin [48]. This finding supports our experimental results reporting less volume of dentin removed.

An ex vivo study of the shaping ability evaluation of 2Shape, NeoNiTi, and Protaper Next systems in severely curved root canals at different canal levels was conducted by Hussien et al. They concluded no statistically significant difference in amounts of mesiodistal canal transportation between the systems at three canal 
levels. All the files system showed some degree of canal transportation. [50].

The results of the present study demonstrated that both rotary systems had comparable values of canal transportation and centering ability among the canal levels. The NeoNiTi files showed less canal aberrations compared to 2 Shape files. These findings might be attributed to the improvement in flexibility of the NeoNiTi instruments due to CM Wire technology and manufactured (EDM) method, which makes the file respect the canals anatomy and improves negotiation of curvatures $[51,52]$.

In the 2Shape group, one case of broken instrument occurred which did not occur in the NeoNiTi group. Moreover, the 2Shape system design features a triplehelix cross-sectional, whereas the NeoNiTi system has a homothetic-rectangle cross-section. The design of the NeoNiTi file is likely associated with the increased fatigue resistance compared to the 2Shape file. Consequently, using this system seems to be safer regarding file breakage. These findings are in conformity with the results of Ozyurek et al. [53], who found that the 2Shape within canal curvatures showed a significantly lower resistance to cyclic fatigue.

Wu et al. reported transportation at apical third greater than $0.3 \mathrm{~mm}$, thus indicating a capability of adversely influencing the sealing ability of root canal filling materials and treatment prognosis [54]. In the present study, the amount of canal transportation for the two evaluated systems (2Shape and NeoNiTi) remained beneath this limit.

The key message for the clinicians is that when used clinically, the NeoNiTi system may perform better and produce more centered preparation and minimal canal deviation compared to the 2 Shape system. Consequently, the null hypothesis in our study was rejected. However, the present study contains several limitations. For instance, it was performed on extracted teeth and thus did not fully represent the conditions present in the oral cavity that might produce different angulation and inclination, which would in turn affect the root canal preparation. Further in-vivo studies are necessary to accurately assess the effect of file designs on the shape of root canals with different morphological patterns.

\section{Conclusions}

Within the limitations of our in vitro study, we conclude that both 2Shape and NeoNiTi systems with severely curved canals were relatively safe in preparation and respected original canal anatomy. Nevertheless, NeoNiTi instruments produced more centered preparation and minimal canal deviation compared to the 2Shape system.

\section{Abbreviations}

NiTi: Nickel-titanium; Micro CT: Micro Computed Tomography; EDM: Electrical discharge machining; CM: Controlled Memory; NaOCl: Sodium Hypochlorite.

\section{Acknowledgements \\ Not applicable.}

\section{Authors' contributions}

Conceived and designed the study: IF, RS MA and ZN. Literature search, study inclusion, data extraction: IF. Analyzed the data: IF, RS, MA and ZN. Prepared the manuscript: IF and ZN. All authors read and approved the final manuscript.

\section{Funding}

None.

Availability of data and materials

All co-authors agree to disclose publicly for all available datasets presented in the main paper.

\section{Declarations}

\section{Ethics approval and consent to participate}

The Research Ethics Committee approval (\# 113-11-20) at King Abdulaziz University, Jeddah, Saudi Arabia. This is a lab study and there is no need for any permissions from participations.

Consent for publication

Not applicable.

\section{Competing interests}

The authors declare that they have no conflict of interests.

\section{Author details}

${ }^{1}$ Department of Endodontics, Faculty of Dentistry, King Abdulaziz University, Jeddah, Saudi Arabia. ${ }^{2}$ Department of Dental Public Health, Faculty of Dentistry, King Abdulaziz University, Jeddah, Saudi Arabia.

Received: 15 June 2021 Accepted: 9 November 2021

Published online: 19 November 2021

\section{References}

1. Sjogren U, Figdor D, Persson S, Sundqvist G. Influence of infection at the time of root filling on the outcome of endodontic treatment of teeth with apical periodontitis. Int Endod J. 1997;30:297-306.

2. Shuping GB, Orstavik D, Sigurdsson A, Trope M. Reduction of intracanal bacteria using nickel- titanium rotary instrumentation and various medications. J Endod. 2000;26:751-5.

3. Schilder H. Cleaning and shaping the root canal. Dent Clin North Am. 1974;18:269-96.

4. Ashwini TS, Bhandari S. The influence of cervical preflaring of root canal on determination of initial apical file using Gates Glidden drills, Protaper, Race and diamond-coated Galaxy files. J Contemp Dent Pract. 2012;13:554-8.

5. Glossen CR, Haller RH, Dove SB, del Rio CE. A comparison of root canal preparations using $\mathrm{Ni}$-Ti hand, $\mathrm{Ni}$-Ti engine-driven, and K-Flex endodontic instruments. J Endod. 1995;21:146-51.

6. Fornari VJ, Silva-Sousa T, Vanni JR. Histological evaluation of the effectiveness of increased apical enlargement for cleaning the apical third of curved canals. Int Endod J. 2010;43:988-94.

7. Roane JB, Sabala CL, Duncanson MG Jr. The "'balanced force"' concept for instrumentation of curved canals. J Endod. 1985;11:203-11.

8. Peters $\mathrm{OA}$, Peters $\mathrm{Cl}$, Basrani B. Cleaning and shaping the root canal system. In: Hargreaves KM, Berman LH, editors. Cohen's pathways of the pulp. 11th ed. St Louis: Elsevier; 2016. p. 209-79.

9. Siqueira JF Jr, Lopes HP. Chemomechanical preparation. In: Siqueira JF, editor. Treatment of endodontic infections. London: Quintessence Publishing; 2011. p. 236-84. 
10. shape brochure. Available at:http://micro-mega.com/shaping/2shape/? langen. Accessed 3, 2017.

11. Micro-Mega. The 2Shape Brochure. Available at: http://micro-mega.com/ wp-

12. Han F, Jiang J, Yu D. Influence of discharge current on machined surfaces by thermo-analysis in finish cut of WEDM. Int J Mach Tools Manuf. 2007:47:1187-96.

13. Pirani C, lacono F, Generali L, Sassatelli P, Nucci C, Lusvarghi L, Gandolfi M, Prati C. HyFlex EDM: superficial features, metallurgical analysis and fatigue resistance of innovative electro discharge machined NiTi rotary instruments. Int Endod J. 2016;49:483-93.

14. Alidoosti A, Ghafari-Nazari A, Moztarzadeh F, Jalali N, Moztarzadeh S, Mozafari M. Electrical discharge machining characteristics of nickel-titanium shape memory alloy based on full factorial design. J Intell Mater Syst Struct. 2013;24:1546-56.

15. Gupta R, Dhingra A, Aggarwal N, Yadav V. A new approach to single file endodontics: neoniti rotary file system. Int Endod J. 2015;2:1030-2.

16. Aminsobhani M, Meraji N, Sadri E. Comparison of cyclic fatigue resistance of five nickel titanium rotary file systems with different manufacturing techniques. J Dent (Tehran). 2015;12:636-46.

17. Schneider SW. A comparison of canal preparations in straight and curved root canals. Oral Surg Oral Med Oral Pathol. 1971;32:271-5.

18. Busquim S, Cunha RS, Freire L, Gavini G, Machado ME. Santos MA A micro-computed tomography evaluation of long-oval canal preparation using reciprocating or rotary systems. Int Endod J. 2014;48:1001-6.

19. Özyürek T, Gündoğar M, Uslu G, YIImaz K, Staffoli S, Nm G. Cyclic fatigue resistances of Hyflex EDM, WaveOne gold, Reciproc blue and 2shape NiTi rotary files in different artificial canals. Odontology. 2018;105:408-13.

20. Thomposon SA, Dummer PM. Shaping ability of hero 642 rotary nickeltitanium instruments in simulated root canals: part 2. Int Endod J. 2000;33:255-61.

21. Gambill JM, Alder M, et al. Comparison of nickel-titanium and stainlesssteel hand file instrumentation using computed tomography. J Endod. 1996;22:369-75.

22. Jafarzadeh $\mathrm{H}$, Abbott PV. Ledge formation: review of a great challenge in endodontics. J Endod. 2007:33:1155-62.

23. Peters OA, Laib A, et al. Three-dimensional analysis of root canal geometry by high-resolution computed tomography. J Dent Res. 2000;79:1405-9.

24. Stern S, Patel S, Foschi F, Sherriff M, Mannocci F. Changes in centring and shaping ability using three nickel-titanium instrumentation techniques analysed by micro-computed tomography $(\mu \mathrm{CT})$. Int Endod J. 2012;45:514-23.

25. Topcuolglu HS, Duzgun S, Akti A, et al. Laboratory comparison of cyclic fatigue resistance of WaveOne Gold, Reciproc and WaveOne files in canals with a double curvature. Int Endod J. 2017;50:713-7.

26. Aminsobhani M, Khoshdel A, Ghorbanzadeh A. The effect of root canal preparation using single versus multiple endodontic rotary files on postoperative pain, a randomised clinical trial. Eur Endod J. 2017;2:1-5.

27. Hyflex EDM directions for use: available at: https://www.coltene.com/ fileadmin/Data/EN/Products/Endodontics/Root_Canal_Shaping/Hy Flex_EDM/31328A_HyFlexEDM_Brochure_US.pdf Accessed December 20, 2017.

28. American Association of Endodontists. Glossary of endodontic terms. 7th ed. Chicago: AAE; 2003.

29. Vallaeys K, Chevailer V. Comparative analysis of canal transportation and centring ability of three Ni-Ti rotary endodontic systems: Protaper, MTwo and Revo-STM, assessed by micro- computed tomography. Odontology. 2016;104:83-8.

30. Al-Hadlaq SM, Aljarbou FA. AlThumairy RI Evaluation of cyclic flexural fatigue of M- wire nickel-titanium rotary instruments. J Endod. 2010;36:305-7.

31. Gao Y, Shotton V, Wilkinson K, Phillips G. Johnson WB Effects of raw material and rotational speed on the cyclic fatigue of ProFile Vortex rotary instruments. J Endod. 2010;36:1205-9.

32. Ceyhanli KT, Kamaci A, Taner M, Erdilek N, Celik D. Shaping ability of two M-wire and two traditional nickel-titanium instrumentation systems in S-shaped resin canals. Niger J Clin Pract. 2015;18(6):713-7.

33. Cui Z, Wei Z, Du M, Yan P, Jiang H. Shaping ability of protaper next compared with waveone in late-model three-dimensional printed teeth. BMC Oral Health. 2018;18:115.
34. Shen Y, Zhou HM, Zheng YF, Campbell L, Peng B, Haapasalo M. Metallurgical characterization of controlled memory wire nickel-titanium rotary instruments. J Endod. 2011:37:1566-71.

35. Peters OA, Gluskin AK, Weiss RA, Han JT. An in vitro assessment of the physical properties of novel Hyflex nickel-titanium rotary instruments. Int Endod J. 2012;45:1027-34.

36. Mozzami K, Nabavizadeh H. Cone-beam computed tomography assessment of root canal transportation by neoniti and reciproc single-file systems. Iran Endod. 2016;11(2):96-100.

37. Forghani M, Hezarjaribi M, Teimouri H. Comparison of the shaping characteristics of Neolix and Protaper Universal systems in preparation of severely curved simulated canals. J Clin Exp Dent. 2017;9(4):e556-9.

38. Gergi R, Osta N, Bourbouze G, et al. Effects of three nickel titanium instrument systems on root canal geometry assessed by micro-computed tomography. Int Endod J. 2015;48:162-70.

39. Loizides AL, Kakavetsos VD, Tzanetakis GN, et al. A comparative study of the effects of two nickel-titanium preparation techniques on root canal geometry assessed by microcomputed tomography. J Endod. 2007:33:1455-9.

40. Elnaghy AM, Elsaka SE. Evaluation of root canal transportation, centering ratio, and remaining dentin thickness associated with ProTaper next instruments with and without glide path. J Endod. 2014;40:2053-6.

41. Coldero LG, McHugh S, Mackenzie D. Reduction in intracanal bacteria during root canal preparation with and without apical enlargement. Int Endod J. 2002;35:437-46.

42. Crumpton BJ, Goodell GG, McClanahan SB. Effects on smear layer and debris removal with varying volumes of $17 \%$ REDTA after rotary instrumentation. J Endod. 2005;31:536-8.

43. Silva EJ, Pacheco PT, Pires F. Microcomputed tomographic evaluation of canal transportation and centring ability of ProTaper Next and Twisted File Adaptive systems. Int Endod J. 2017:50:694-9.

44. Setzer FC, Kwon TK, Karabucak B. Comparison of apical transportation between two rotary file systems and two hybrid rotary instrumentation sequences. J Endod. 2010;36:1226-9.

45. Gluskin AH, Brown DC. A reconstructed computerized tomographic comparison of NiTi rotary GTTM files versus traditional instruments in canals shaped by novice operators. Int Endod J. 2001;34:476-84.

46. Madani Z, Soleymani A, Bagheri T, Moudi E, Bijani A, Rakhshan V. Transportation and Centering Ability of Neoniti and protaper Instruments. A CBCT assessment Iran Endod J. 2017;12:43-9.

47. Rubio J, Zarzosa Jl, Pallarés A. Comparison of shaping ability of 10 rotary and reciprocating systems: an in vitro study with AutoCAD. Acta Stomatol Croat. 2017;51:207-16.

48. Natto ZS, Parashis A, Steffensen B, Ganguly R, Finkelman MD, Jeong YN . Efficacy of collagen matrix seal and collagen sponge on ridge preservation in combination with bone allograft: A randomized controlled clinical trial. J Clin Periodontol. 2017:44:649-59.

49. Singh S, Mirdha N, Shilipa PH, Tiwari RVC, Abdul MSM, Sainudeen S. Shaping ability of 2Shape and WaveOne Gold files using cone-beam computed tomography. J Int Soc Prev Community Dent. 2019;9(3):245-9.

50. Hussien YH, Roshdy NN, Ghoniem AG. Assessment of the Shaping Abilities of 2Shape, Neolix and pro taper next rotary systems: a comparative in vitro study. Acta Sci Dent Sci. 2020;4:71-8.

51. Turpin YL, Chagneau F, Vulcain JM. Impact of two theoretical crosssections on torsional and bending stresses of nickel-titanium root canal instrument models. J Endod. 2000;26:414-7.

52. Schafer E, Dzepina A, Danesh G. Bending properties of rotary nickeltitanium instruments. Oral Surg Oral Med Oral Pathol Oral Radiol Endod. 2003;96:757-63.

53. Özyürek T, Gündoğar M, Uslu G, Y,lmaz K, Staffoli S, Nm G. Cyclic fatigue resistances of Hyflex EDM, WaveOne gold, Reciproc blue and 2shape NiTi rotary files in different artificial canals. Odontology. 2018;106:408-13.

54. Wu M-K, Fan B, Wesselink PR. Leakage along apical root fillings in curved root canals. Part l: effects of apical transportation on seal of root fillings. J Endod. 2000;26:210-6.

\section{Publisher's Note}

Springer Nature remains neutral with regard to jurisdictional claims in published maps and institutional affiliations. 